\title{
Sistem Pendeteksi Jatuh Wearable untuk Lanjut Usia Menggunakan Accelerometer dan
} Gyroscope

\author{
Syifa Dzikri Tsani dan Indra Hardian Mulyadi* \\ Politeknik Negeri Batam, Batam, Indonesia \\ *Email: indra@polibatam.ac.id
}

\begin{abstract}
Abstrak- Perkembangan populasi lanjut usia meningkat setiap tahunnya berbanding lurus dengan angka potensi jatuh pada lanjut usia. Jatuh menjadi salah satu kecelakaan yang paling umum terjadi pada lanjut usia. Sekitar $28-35 \%$ orang berusia 65 atau lebih di dunia mengalami kejadian jatuh setiap tahunnya. Jatuh dapat berakibat cedera fatal bahkan meningkatkan risiko kematian jika tidak segera ditangani. Untuk meminimalkan dampak yang ditimbulkan jatuh tersebut, telah banyak penelitian yang dilakukan salah satunya dengan metode threshold. Penelitian ini bertujuan membuat suatu sistem pendeteksi jatuh untuk mendapatkan nilai akurasi sistem. Sistem ini memanfaatkan nilai keluaran dari sensor accelerometer dan gyroscope berbasis mikrokontroler dengan metode threshold. Hasil notifikasi jatuh akan dikirimkan dan ditampilkan pada smartphone android. Perangkat ini bersifat wearable digunakan pada bagian pinggang. Penelitian ini menggunakan 6 jenis aktivitas biasa: berdiri, jongkok, berjalan, berlari, naik dan turun tangga, juga menggunakan 4 jenis aktivitas jatuh: jatuh ke kanan, kiri, depan dan belakang. Berdasarkan hasil pengujian yang telah dilakukan, didapatkan bahwa sistem yang dibuat memiliki sensitivitas sebesar 82,50\%, spesifisitas sebesar $91,67 \%$, akurasinya sebesar $88 \%$ dan tingkat keberhasilan smartphone menampilkan notifikasi jatuh sebesar $96,97 \%$.
\end{abstract}

Kata kunci: lanjut usia, accelerometer, gyroscope, threshold, wearable

\section{INTRODUCTION}

SESEORANG yang telah memasuki usia 60 tahun atau lebih dapat dikategorikan sebagai lanjut usia. Lanjut usia merupakan kelompok umur manusia yang telah memasuki tahapan akhir dari fase kehidupannya. Populasi global orang berusia 60 tahun atau lebih berjumlah 962 juta pada tahun 2017. Jumlah tersebut diperkirakan akan berlipat ganda pada tahun 2050 mencapai hampir 2,1 miliar jiwa [1]. Sedangkan di Indonesia, berdasarkan data proyeksi penduduk oleh Badan Pusat Statistik [2], pada tahun 2017 populasi lanjut usia mencapai 23,66 juta jiwa. Diperkirakan jumlah penduduk lanjut usia di Indonesia pada tahun 2030 mencapai 40,95 juta jiwa [3].

Jatuh menjadi kecelakaan yang paling umum terjadi pada lanjut usia. Menurut Centers for Disease Control and Prevention, satu dari tiga orang lanjut usia mengalami jatuh setiap tahunnya. Jatuh dapat berakibat fatal jika tidak segera ditangani karena dapat menyebabkan patah tulang, cedera kepala, cacat bahkan meningkatkan risiko kematian [4]. Pengawasan dan penanganan segera terhadap lanjut usia oleh orang terdekat atau anggota keluarganya penting dilakukan, untuk meminimalkan dampak yang ditimbulkan oleh jatuh tersebut. Namun, tidak semua anggota keluarga dapat terus menemani dan berada di dekat lanjut usia, karena memiliki aktivitas lainnya. Sehingga dibutuhkan suatu perangkat atau sistem sebagai solusi yang dapat memberikan notifikasi jika terjadi jatuh pada lanjut usia.

Saat ini sistem pendeteksi jatuh sedang dikembangkan. Sebagian besar didasarkan pada sensor optik (kamera), accelerometer dan kombinasi accelerometer dengan gyroscope. Beberapa metode untuk mendeteksi orang jatuh telah ada seperti ambang batas (threshold) dan machine learning. Metode machine learning memiliki akurasi yang baik. Namun, membutuhkan biaya komputasi yang tinggi, ukuran fisik yang besar dan konsumsi energi yang tinggi [5]. Meski akurasi dari metode threshold tidak sebaik machine learning, namun metode ini lebih cocok digunakan pada perangkat yang dapat dipakai dan konsumsi energi yang rendah. Karena perhitungan metode ini sederhana dan dapat diimplementasikan pada perangkat dengan ukuran kecil $[5,6]$. Pada penelitian ini kami membuat suatu perangkat yang dapat mendeteksi jatuh yang harapannya dapat digunakan oleh lanjut usia menggunakan sensor accelerometer dan gyroscope berbasis mikrokontroler. Sistem ini memanfaatkan nilai keluaran dari sensor berupa percepatan dan kecepatan sudut dari pengguna. Hasil penelitian ini, sistem mudah untuk digunakan, karena didesain wearable dan dapat mendeteksi aktivitas biasa dan jatuh. Sistem ini juga dilengkapi dengan beberapa fitur seperti menggunakan baterai dengan konsumsi daya rendah, memberikan alert pada perangkat berupa buzzer dan dapat mengirimkan hasil notifikasi jatuh ke smartphone orang terdekat atau anggota keluarganya untuk segera dilakukan penanganan. 


\section{Metode}

Sistem pendeteksi jatuh yang dibuat terdiri dari beberapa komponen utama seperti mikrokontroler, sensor, power supply, dan bluetooth. Sistem ini juga terhubung dengan smartphone melalui bluetooth, seperti pada diagram blok sistem yang dapat dilihat pada Gambar 1 dan Gambar 2.

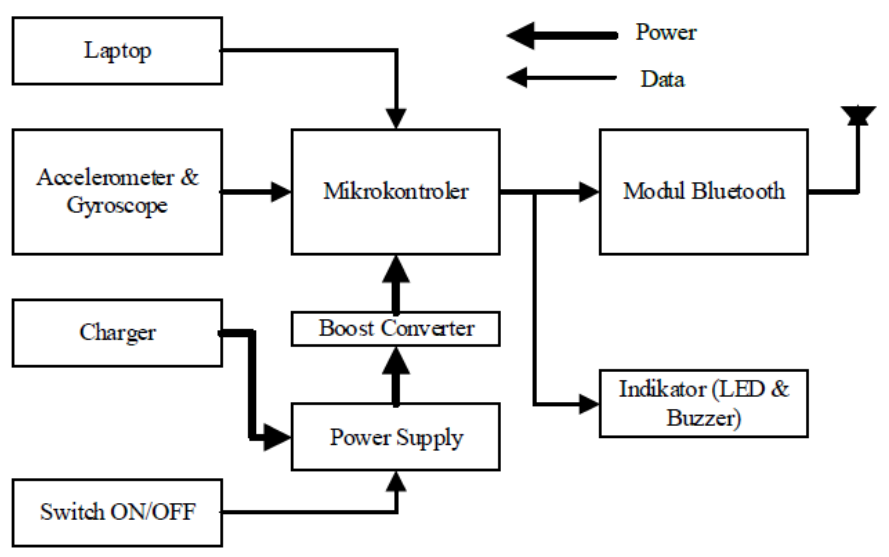

Gambar 1. Diagram blok sistem pada perangkat keras

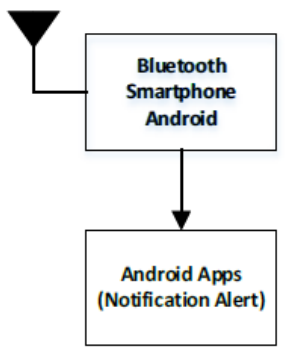

Gambar 2. Diagram blok sistem pada smartphone

\section{A. Sistem}

Sistem pendeteksi jatuh yang dibuat terdiri atas beberapa komponen utama seperti mikrokontroler, sensor, power supply, dan bluetooth. Sistem ini juga terhubung dengan smartphone melalui bluetooth, seperti pada diagram blok sistem yang dapat dilihat pada Gambar 1, Gambar 2, dan realisasi perangkat pada Gambar 3. Beberapa komponen penyusun sistem ini antara lain:

\section{1) Mikrokontroler}

Mikrokontroler yang digunakan adalah Arduino Nano v3.1 sebagai pengontrol sistem.

\section{2) Modul Sensor}

Modul MPU-6050 digunakan untuk mendapatkan nilai keluaran dari percepatan dan kecepatan sudut untuk mendeteksi jatuh.

\section{3) Power Supply}

Baterai lithium-ion digunakan sebagai power supply eksternal memiliki tegangan sebesar $3.7 \mathrm{~V}$ yang dinaikan menjadi $5 \mathrm{~V}$ dengan modul boost converter dan dilengkapi dengan modul charger.

\section{4) Bluetooth}

Modul bluetooth yang digunakan adalah HC-05 untuk menghubungkan sistem dengan smartphone.

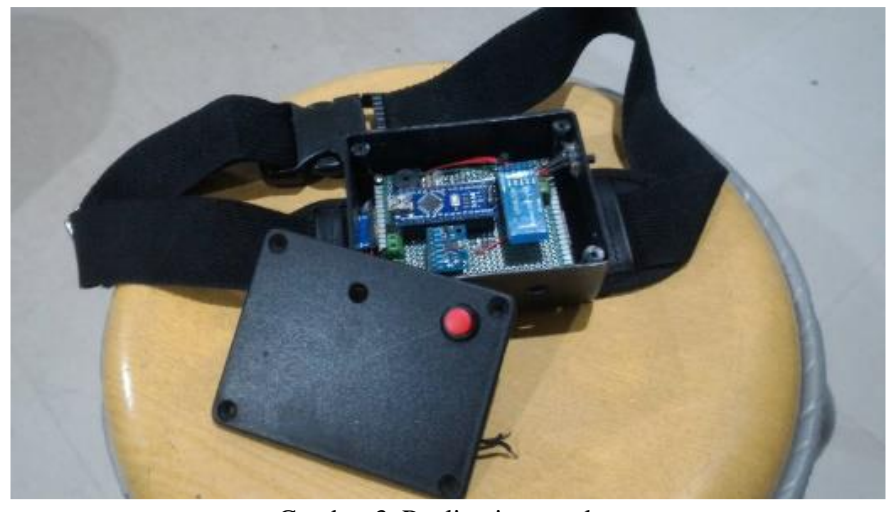

Gambar 3. Realisasi perangkat

Sistem ini bersifat wearable artinya dapat digunakan pada badan penggunanya. Perangkat digunakan pada posisi pinggang seperti pada Gambar 4.

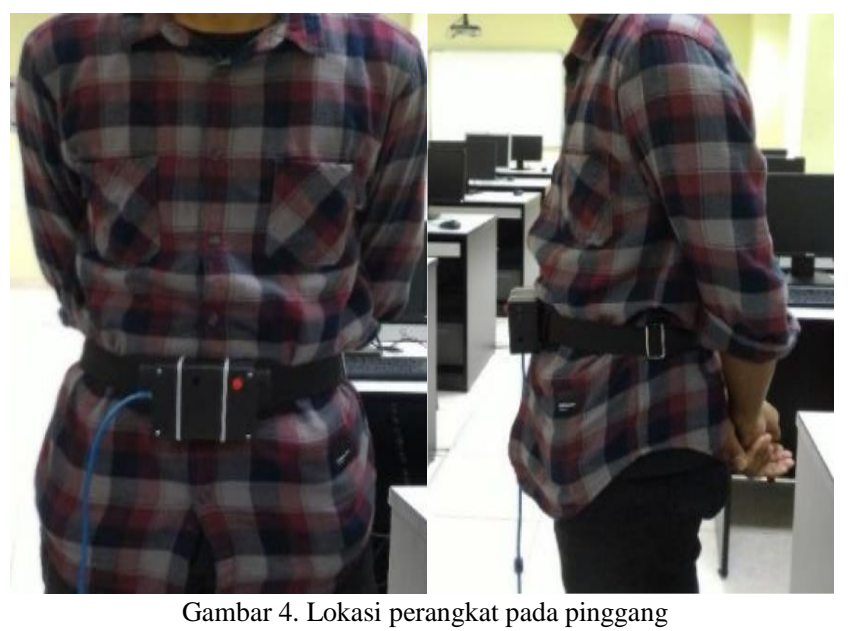

\section{B. Metode Threshold}

Metode ambang batas (threshold) merupakan salah satu metode yang digunakan dalam algoritma klasifikasi aktivitas jatuh dan aktivitas biasa. [5-7]. Penentuan nilai threshold dilakukan dengan menganalisis semua nilai total percepatan dan total orientasi dari gerak aktivitas biasa atau activity of daily living (ADL), kemudian diambil nilai maksimalnya untuk dijadikan nilai threshold [5]. Pada metode threshold parameter yang digunakan adalah total Accelerometer Magnitude (AM) dan total kecepatan sudut atau total orientasi Gyroscope Magnitude (GM).

Total percepatan dapat dihitung dengan persamaan (1), dimana $A C C_{x}, A C C_{y}$, dan $A C C_{z}$ adalah gravitasi percepatan pada sumbu $x, y$, dan $z$.

$$
A M=\sqrt{\left(A C C_{x}\right)^{2}+\left(A C C_{y}\right)^{2}+\left(A C C_{z}\right)^{2}}
$$

Kemudian untuk menghitung total kecepatan sudut dapat digunakan dalam persamaan (2), dimana Gyro $_{x}$, Gyro $_{y}$, dan Gyro $_{z}$ adalah kecepatan sudut sumbu $x, y$, dan $z$ [5]. 


$$
G M=\sqrt{\left(\text { Gyro }_{x}\right)^{2}+\left(\text { Gyro }_{y}\right)^{2}+\left(\text { Gyro }_{z}\right)^{2}}
$$

Pada penelitian ini terdapat tiga threshold yang digunakan untuk mendeteksi jatuh an yaitu UFTacc (Upper Fall Threshold), LFTacc (Lower Fall Threshold) dan UFTgy (Upper Fall Threshold). Pada sistem pendeteksi jatuh ini data hasil pembacaan sensor akan diolah menggunakan algoritma pendeteksi jatuh dengan metode threshold yang sudah ada [5] seperti pada Gambar 5.

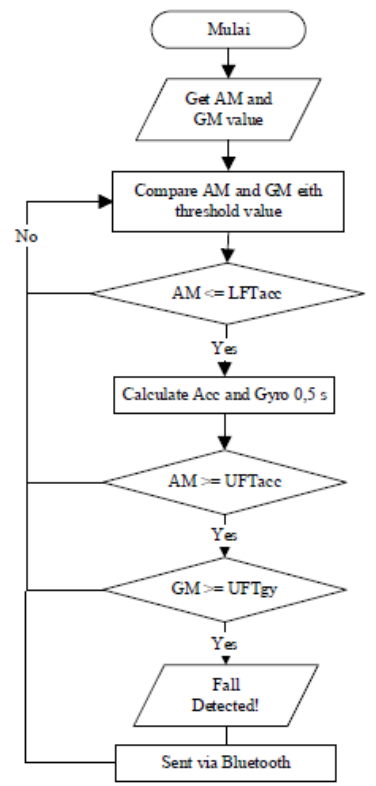

Gambar 5. Flowchart algoritma pendeteksi jatuh

\section{Desain Pengujian}

Pada penelitian ini kami menggunakan parameter spesifitas, sensitivitas dan akurasi untuk mengetahui tingkat kehandalan dari sistem yang dibuat. Untuk menghitung masing-masing parameter tersebut dengan menggunakan persamaan (3), (4) dan (5):

$$
\begin{gathered}
\text { Spesifisitas }=\frac{T N}{T N+F P} \\
\text { Sensitivitas }=\frac{T P}{T P+F N} \\
\text { Akurasi }=\frac{T P+T N}{T P+F P+T N+F N}
\end{gathered}
$$

Terdapat empat kondisi umum dalam sistem deteksi jatuh sebagai nilai dalam pengukuran, yaitu [5,7]:

1) True Positive (TP), kondisi sistem mendeteksi sebagai aktivitas jatuh, ketika aktivitas jatuh.

2) True Negative (TN), kondisi sistem mendeteksi sebagai aktivitas tidak jatuh, ketika aktivitas tidak jatuh.

3) False Positive (FP), kondisi sistem mendeteksi sebagai aktivitas jatuh, ketika aktivitas tidak jatuh.

4) False Negative (FN), kondisi sistem mendeteksi sebagai aktivitas tidak jatuh, ketika aktivitas jatuh.

Pada penelitian ini pengujian sistem dilakukan dengan membuat desain beberapa aktivitas yang dibagi menjadi kategori aktivitas jatuh dan aktivitas biasa seperti pada Table I $[7,8]$.

TABEL I

DESAIN PENGUJIAN SISTEM

\begin{tabular}{|l|l|}
\hline \multirow{2}{*}{ Kategori } & \multicolumn{1}{|c|}{ Aksi } \\
\hline \multirow{4}{*}{$\begin{array}{l}\text { Aktivitas } \\
\text { Jatuh }\end{array}$} & Jatuh ke Kanan \\
\cline { 2 - 2 } & Jatuh ke Kiri \\
\cline { 2 - 2 } & Jatuh ke Depan \\
\cline { 2 - 2 } & Jatuh ke Belakang \\
\hline \multirow{4}{*}{$\begin{array}{l}\text { Aktivitas } \\
\text { Biasa }\end{array}$} & Berdiri \\
\cline { 2 - 2 } & Berdiri - Jongkok \\
\cline { 2 - 2 } & Berjalan \\
\cline { 2 - 2 } & Berlari \\
\cline { 2 - 2 } & Naik Tangga \\
\cline { 2 - 2 } & Turun Tangga \\
\hline
\end{tabular}

\section{HASIL DAN DISKUSI}

Berdasarkan hasil pengujian, Gambar 6-9 menunjukkan nilai Accelerometer Magnitude (AM) dan Gyroscope Magnitude (GM) dari beberapa aktivitas sesuai dengan desain pengujian.

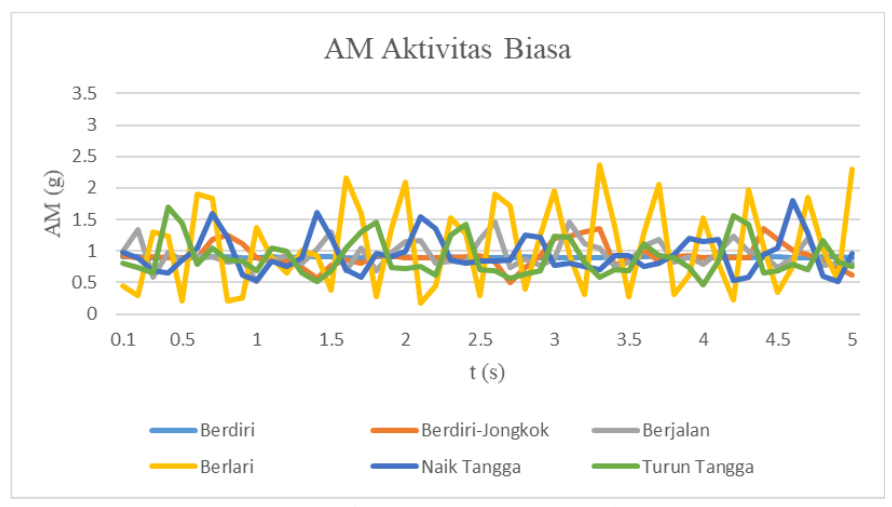

Gambar 6. Grafik hasil AM pada aktivitas biasa

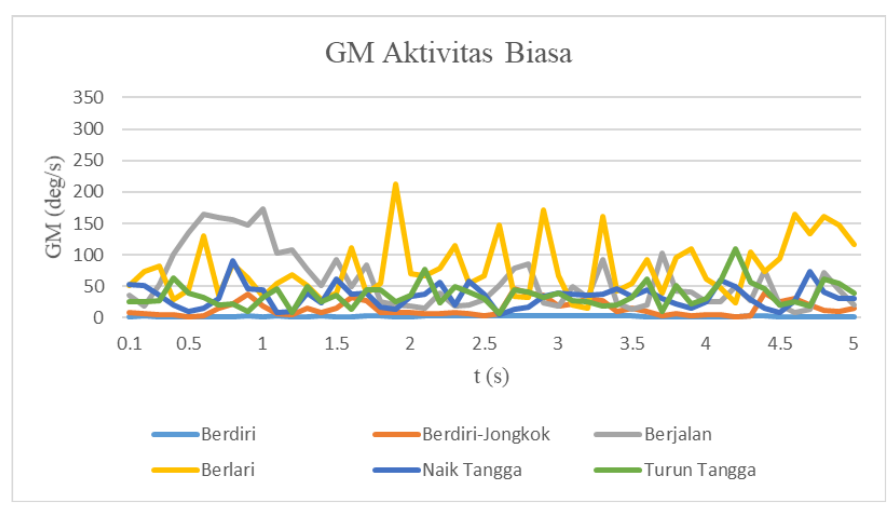

Gambar 7. Grafik Hasil GM pada aktivitas biasa 


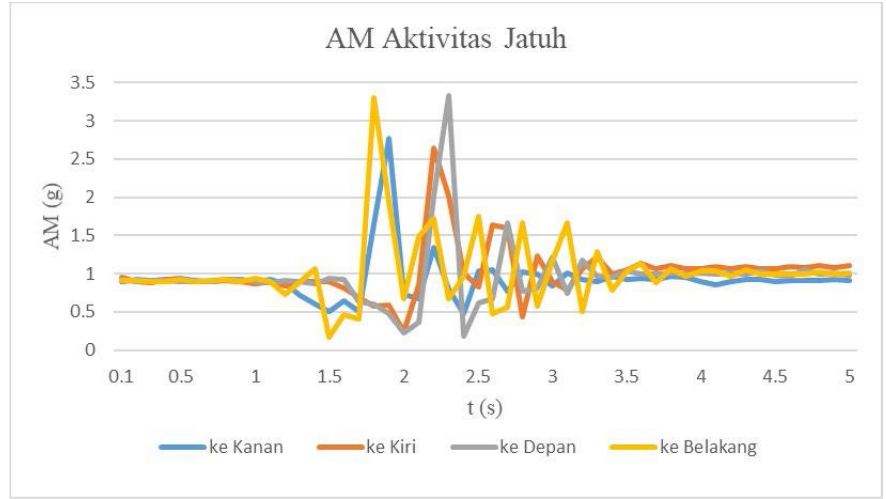

Gambar 8. Grafik hasil AM pada aktivitas jatuh

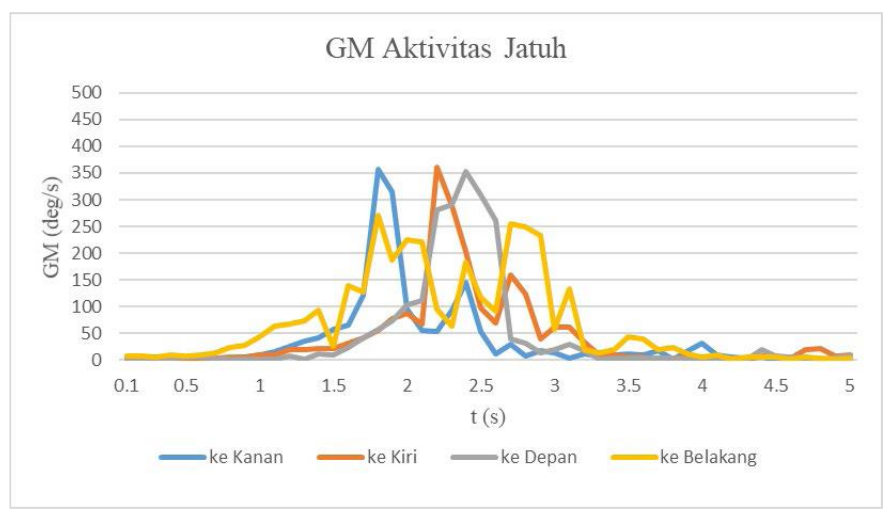

Gambar 9. Grafik hasil AM pada aktivitas jatuh

Berdasarkan grafik pada Gambar 6-9 dan berdasarkan hasil observasi [5], maka nilai threshold LFTacc dan UFTacc yang akan digunakan adalah $0.48 \mathrm{~g}$ dan $2,36 \mathrm{~g}$. Sedangkan untuk UFTgy sebesar $270 \mathrm{deg} / \mathrm{s}$.

Berdasarkan hasil yang didapatkan dari pengujian sistem yang dilakukan dengan menggunakan nilai threshold yang telah ditentukan, maka didapatkan hasil parameter pengukuran seperti pada Tabel II.

TABEL II

HASIL PARAMETER PENGUJIAN SISTEM
\begin{tabular}{|c|c|}
\hline Parameter Pengujian & Jumlah \\
\hline TP & 33 \\
\hline TN & 55 \\
\hline FP & 5 \\
\hline FN & 7 \\
\hline
\end{tabular}

$$
\begin{gathered}
\% \text { Spesifisitas }=\frac{55}{55+5} \times 100 \%=91.67 \% \\
\% \text { Sensitivitas }=\frac{33}{33+7} \times 100 \%=82.5 \% \\
\% \text { Akurasi }=\frac{33+55}{33+55+5+7} \times 100 \%=88 \%
\end{gathered}
$$

Dari 40 percobaan aktivitas jatuh, sebanyak 33 kali berhasil terdeteksi sebagai jatuh dan notifikasi yang ditampilkan di android sebanyak 32 kali. Sehingga persentase keberhasilan notifikasi yang ditampilkan di android sebesar 96,97\%.

$$
\% \text { Akurasi Notifikasi }=\frac{32}{33} \times 100 \%=96.97 \%
$$

Gambar 10 menunjukkan aplikasi android yang telah dibuat berhasil menampilkan hasil deteksi jatuh ketika perangkat mendeteksi aktivitas jatuh.

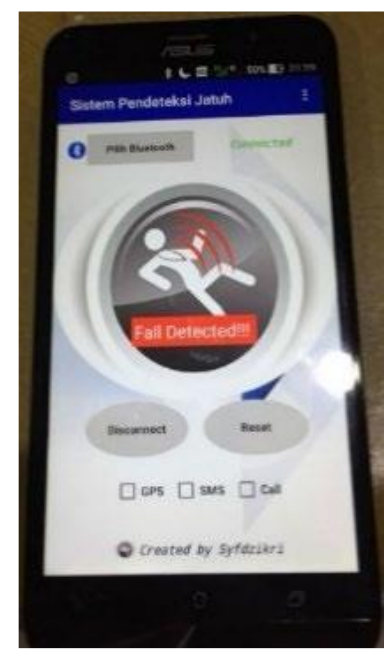

Gambar 10. Aplikasi Android menampilkan hasil deteksi jatuh

\section{KESIMPULAN}

Sistem yang dibuat berhasil mendeteksi aktivitas biasa dan jatuh. Hasil pengujian keseluruhan alat dengan menggunakan nilai threshold LFTacc, UFTac dan UFTgy sebesar 0,48 g, $2,36 \mathrm{~g}$. dan $270 \mathrm{deg} / \mathrm{s}$, maka didapatkan sensitivitas sebesar $82,50 \%$, spesifisitas sebesar $91,67 \%$, dan akurasinya sebesar $88 \%$. Hasil notifikasi jika terjadi jatuh dapat ditampilkan pada aplikasi android smartphone dengan tingkat keberhasilan sebesar $96,97 \%$.

\section{UCAPAN TERIMA KASIH}

Penelitian ini didanai oleh Direktorat Jenderal Tinggi Pendidikan, DIKTI dan Politeknik Negeri Batam.

\section{REFERENCES}

[1] United Nations, "World Population Ageing 2017- Highlights (ST/ESA/SER.A/397).”in Economic \& Social Affairs, Ed. New York: Department of Economic and Social Affairs, Population Division, 2017.

[2] Kementrian Kesehatan RI. "Analisis Lansia di Indonesia." Pusat data informasi, 2017.

[3] World Health Organization, "WHO Global Report on Falls Prevention in Older Age." in Ageing and Life Course, Family and Community Heal th, Ed. Avenue Appia, Switzerland: WHO Press, Population Division, 2017.

[4] Centers for Disease Control and Prevention. "Important Facts about Falls." Internet: https://www.cdc.gov/homeandrecreationalsafety/falls/adultfalls, Feb. 10, 2017 [Mar. 01, 2018].

[5] M. I. Nari, S. S. Suprapto, I. H. Kusumah, "A Simple Design of Wearable Device for Fall Detection with Accelerometer and Gyroscope.” 2016 International Symposium on Electronics and Smart Devices (ISESD), November 29-30, 2016.

[6] A. Kurniawan, A. R. Hermawan, I.K.E Purnama "A Wearable Device for Fall Detection Elderly People Using Tri Dimensional Accelerometer." 2016 International Seminar on Intellegent Technology and Its Application, 2016.

[7] S. Norhabibah, W. Andhyka K., D. Risqiwati "Rancang Bangun Sistem Monitoring Deteksi Jatuh untuk Manula dengan Menggunakan Accelerometer." Journal Of Informatics, Network, and Computer 
Science, vol.1, pp.43-52, Nov. 2016.

[8] M. Liandana, I. W. Mustika, Selo. "Pengembangan Sistem Deteksi Jatuh pada Lanjut Usia Menggunakan Sensor Accelerometer pada Smartphone Android." Seminar Nasional Teknologi Informasi dan Komunikasi (SENTIKA 2014). Yogyakarta. ISSN: 2089-9813. 